\title{
Role of Sesame Oil Pulling in the Management of Oral Submucous Fibrosis: A Pilot Study
}

\section{Shriya Khaira ${ }^{1}$, Priyanka Verma ${ }^{1}$ and Sunita Gupta ${ }^{2 *}$}

${ }^{1}$ Senior Resident, Department of Oral Medicine and Radiology, Maulana Azad

Institute of Dental Sciences, New Delhi, India

${ }^{2}$ Professor and Head, Department of Oral Medicine and Radiology, Maulana Azad

Institute of Dental Sciences, New Delhi, India

*Corresponding Author: Sunita Gupta, Professor and Head, Department of Oral

Medicine and Radiology, Maulana Azad Institute of Dental Sciences, New Delhi, India.

DOI: $10.31080 /$ ASDS.2020.04.0897
Received: July 06, 2020

Published: July 28, 2020

(C) All rights are reserved by Sunita Gupta, et al.

\section{Abstract}

Background: Oral Submucous Fibrosis is a progressive, premalignant condition for which multiple treatment modalities have been tried with partial success rate. Oil pulling is a newer treatment modality which involves swishing of oil in the mouth. Sesame oil has been used as it possesses antioxidative properties which prevent free radical injury to oral tissues.

Objective: To find a holistic, cost effective and permanent treatment approach with no side effects.

Materials and method: Twenty clinically and histopathologically diagnosed subjects of oral sub mucous fibrosis were treated by oil pulling procedure for 6 months. All subjects were instructed to perform oil pulling with sesame oil for 15-20 minutes every morning. The parameters recorded on day 0 and at the end of 6 months were mouth opening, tongue protrusion, VAS scale, cheek flexibility and gingival index. Intra group comparison were made using wilcoxon signed rank test.

Result: The pre and post treatment values for mouth opening, tongue protrusion, VAS scale and gingival index were statistically significant $(\mathrm{p}<.0001)$. No statistical significant difference $(\mathrm{p}=.228)$ was noted in cheek flexibility.

Conclusion: The result of this pilot study indicates that sesame oil pulling can be used as a treatment modality in the management of oral sub mucous fibrosis.

Keywords: Oral Sub Mucous Fibrosis; Sesame Oil Pulling; Mouth Opening; VAS Scale; Tongue Protrusion

\section{Introduction}

Oral Submucous Fibrosis is a potentially premalignant oral epithelial lesion involving the oral cavity, oropharynx and upper part of the oesophagus [1]. The consumption of areca nut is the most noticeable causative factor in the initiation of this disorder, although other etiologic factors associated are betel quid and gutkha, chili and spices consumption, genetic susceptibility, smoking along with drinking, immune mediated process and certain dietary deficiencies leads to deranged collagen metabolism [2-4].
One of the most common clinical symptoms is inability to tolerate zesty foods. The earlier phase of the disease manifests as vesicles and ulcers, which are mostly seen on hard palate and buccal mucosa. As the disease progresses it leads to xerostomia, restricted tongue protrusion along with decrease in elasticity of the buccal mucosa, lips and floor of the mouth. Opaque and blanched appearance of the oral mucosa is noted which is attributed to fibrotic bands within the oral mucosa [5].

Eventually, generalized fibrosis occurs leading to trismus. An early and prompt treatment is necessary due to its high malignant 
potential rate. The management of oral submucous fibrosis is varied and includes medical, physical, surgical and lasers according to the different stages of the disorder [6]. However, all these treatment modalities have very limited success, as they have side effects and relapse is also common [7].

This study was planned to find a holistic, natural, cost effective therapeutic modality with minimal/no side effects to the patients of oral submucous fibrosis. Subjects of oral submucous fibrosis were enrolled in this pilot study to assess a natural approach for its management. The technique used is Kavala Graha, also known as oil pulling, a concept introduced by Dr. F. Karach in Russia during 1990's [8]. Oil puling means swishing of the oil in the mouth that can be performed by using sesame oil, coconut oil and sunflower oil [9].

Sesame plant (Sesamum indicum) of the Pedaliaeceae family has been considered as a boon to mankind because of its enhanced health and nutritional qualities. In India, the seeds of sesame are commonly known as 'gingelly' or 'til' seeds [10]. Sesame oil contains three ligans (sesamin, sesamolin and sesaminol) which contain Vitamin E and polyunsaturated fatty acids. In addition, linoleic acid and oleic acid are also major components of sesame oil that possess antioxidative properties that reduce lipid peroxidation by diminishing the free radical injury to tissues [11].

\section{Materials and Methods}

20 clinically and histopathologically proven subjects of oral submucous fibrosis were enrolled in this study, which was performed at Maulana Azad Institute of Dental Sciences, New Delhi in the Department of Oral Medicine and Radiology. The ethical clearance was obtained from the institution ethical committee and the study was registered in CTRI (CTRI/ 2018/08/015166).

\section{Inclusion criteria}

Clinically and histopathologically proven cases of Oral Submucous Fibrosis with mouth opening ranging from 11 - $38 \mathrm{~mm}$. Subjects who were willing to quit habit and gave their consent for regular follow up.

\section{Exclusion criteria}

Subjects who did not give consent for participation, pregnant and lactating females. Subjects having any other premalignant le- sion or white patch and evidence of dysplasia or malignancy histopathologically were excluded.

\section{Study design}

Detailed clinical examination in terms of burning sensation, mouth opening, tongue protrusion, cheek flexibility and gingival index was performed. History of smoking and smokeless habit forms was recorded for each patient (Table 1).

\begin{tabular}{|l|l|}
\hline Forms of habit & \multicolumn{1}{|c|}{ Constituents } \\
\hline $\begin{array}{l}\text { Paan Masala } \\
\text { 16] }\end{array}$ & $\begin{array}{l}\text { Areca nut, catechu, cardamom, lime, natural } \\
\text { and artificial perfuming, and flavoring mate- } \\
\text { ials }\end{array}$ \\
\hline Gutkha [16] & $\begin{array}{l}\text { Areca nut, catechu, cardamom, lime, natural } \\
\text { and artificial perfuming, and flavoring mate- } \\
\text { ials + chewing tobacco }\end{array}$ \\
\hline $\begin{array}{l}\text { Paan/betel } \\
\text { quid [16] }\end{array}$ & $\begin{array}{l}\text { Mixture of areca nut, catechu, and slaked lime } \\
\text { wrapped in a betel leaf. In India, most habital } \\
\text { chewers of of betel quid add tobacco }\end{array}$ \\
\hline Tobacco [12] & $\begin{array}{l}\text { Chewing: in the form of loose leas, plug or } \\
\text { twist } \\
\text { Snuff: finely cutor ground tobacco that can be } \\
\text { dry or moist }\end{array}$ \\
\hline
\end{tabular}

Table 1: Forms of habit and its constituents.

Following measurements were taken

- Mouth opening: It was measured by using a vernier caliper extending from the mesioincisal angle of maxillary central to the mandibular central incisor tooth [12] (Figure 1a and 2a).

- $\quad$ VAS (Visual Analog Scale): VAS was used to assess burning sensation (0-10). Patients were asked to mark the scale and the numeric value was determined from the scale [12].

- Tongue protrusion: For assessing tongue protrusion, one tip of vernier caliper was placed on the tip of the protruded tongue and other, on the mesial contact area of maxillary central incisors. The distance between both these points was recorded [12] (Figure $1 \mathrm{~b}$ and $2 \mathrm{~b}$ ).

- Cheek flexibility (CF): This was measured on a reference line formed by joining the angle of mouth and tragus. The two points were marked in the middle third of this line. The distance between these two points at rest was $V_{1}$ and on full extension of cheek after blowing was $V_{2}$. Cheek flexibility was recorded as the difference between $\mathrm{V}_{2}$ and $\mathrm{V}_{1}\left(\mathrm{CF}=\mathrm{V}_{2}-\mathrm{V}_{1}\right)$ and was measured by using a scale [12]. 
- Gingival index: The gingival was assessed and scores were allocated. 0 for given for normal gingival, 1 was assigned in case of mild inflammation in gingiva with slight edema, no bleeding on probing, score 2 for moderate inflammation in gingival for redness, edema and glazing, associated with bleeding on probing and a score 3 for marked inflammation with marked redness and edema and tendency to bleed spontaneously [13]. An informed consent by all the patients was obtained at the start of the study.

\section{Methodology}

Clinical grading of OSMF was done according to classification given by Haider., et al [14]. These parameters were recorded at the baseline (day 0 ) and then after every 15 days regularly for 6 months. The patients were given the sachets (sesame oil, VVV Sons India) and were instructed to perform oil pulling every day on an empty stomach by emptying the entire content of $10 \mathrm{ml}$ sachet of sesame oil and swishing the oil in the mouth without swallowing it for at least 20 minutes. A good contact of oil was made between with the cheek, around the tongue and hard palate while swishing which was followed by spitting and brushing the teeth. The patients were refrained from eating or drinking anything for half an hour. Along with this, instructions were given to perform physiotherapy exercises with the help of ice cream sticks for opening the mouth. Tobacco cessation centre in our institute motivated all the subjects to quit their habit. A complete oral prophylaxis was performed in all the patients at the start of the treatment. The patients were recalled after every 15 days for a period of 6 months. The statistical analysis was done by applying non parametric wilcoxon signed rank tests.

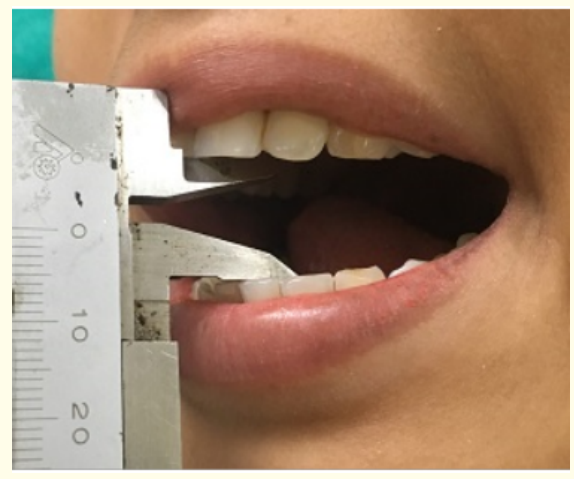

Figure 1a: Pre treatment photograph of patient's mouth opening.

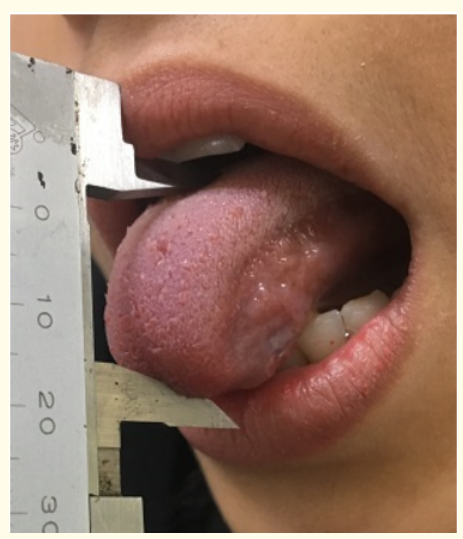

Figure 1b: Pre treatment photograph of patient's tongue protrusion.

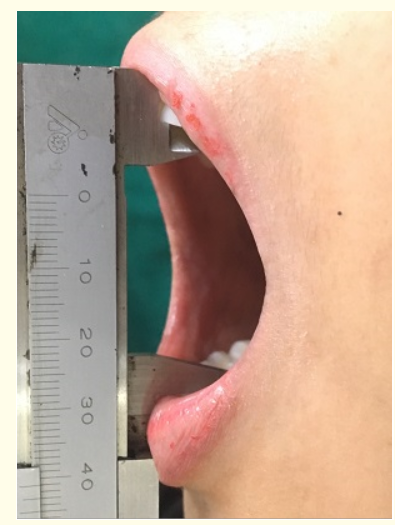

Figure 2a: Post treatment photograph of patient's mouth opening.

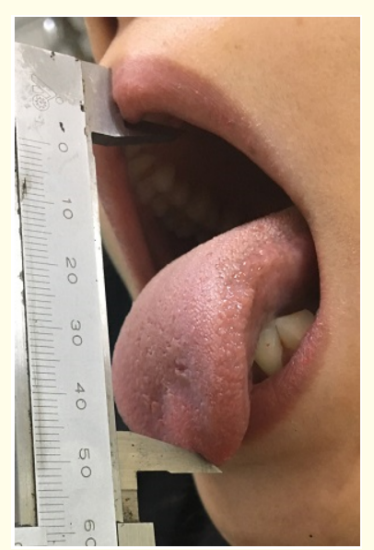

Figure 2b: Post treatment photograph of patient's tongue protrusion. 


\section{Results}

20 subjects ( 6 females, 14 males) with the mean age of 25.1 years were recruited in this pilot study. Depending upon the etiological factors, $45 \%$ had gutkha chewing habit. Betel quid and tobacco chewing was seen in $15.1 \%, 25 \%$ of the subjects showed betel quid, tobacco and smoking, $10.1 \%$ gave a history of paan masala and tobacco, while remaining $5 \%$ had a combined history of consumption of paan masala, alcohol and tobacco (Figure). 17 cases (85\%) were in Group A, 2 (10\%) in Group B and 1 (5\%) patient was in Group C category (Haider., et $a l$ ).

The mean difference in pre and post treatment values of mouth opening was $27.51 \pm 9.086$ and $36.98 \pm 9.6$ respectively. The mean difference of pre and post treatment VAS scale values was $5.45 \pm$ 3.2 and $3.05 \pm 1.93$ respectively. The pre and post treatment mean value difference for tongue protrusion was $41.55 \pm 11.8$ and 52.3 \pm 14.4 respectively. The mean difference in opening of the mouth, tongue protrusion, VAS Scale was significant $(\mathrm{p}<.0001)$. The mean difference in the values of pre and post cheek flexibility was .290 \pm .352 and $.350 \pm .489$ respectively and was not statistically significant $(\mathrm{p}=.228)$. Pre and post values of the gingival index score also showed significant improvement.

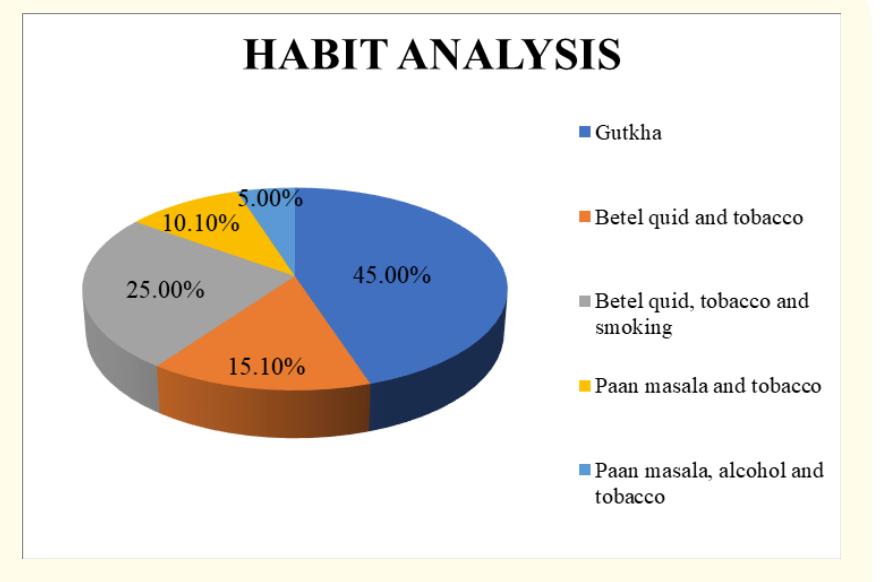

Figure ing $(45 \%)$ and this habit was similar to the findings of previous researchers. ${ }^{15}$ The males were seen to be more affected than females, similar to previous studies. In the present study, the role of topical antioxidants was assessed by using an oil pulling technique with sesame oil. Vitamin $\mathrm{E}$ in sesame oil possess antioxidative properties that reduce lipid peroxidation by diminishing free radical injury to oral tissues [15].

The improvement in mouth opening and tongue protrusion showed significant difference in the present study. This could be attributed to synergistic antioxidant action and mouth opening physiotherapy exercises performed by the patients. Initially, the patients were able to perform the oil pulling procedure for only 5 7 minutes, which was later gradually increased to 20 minutes. This was possibly due to local effect of sesame oil on the buccal mucosa leading to its enhanced mucosal pliability. The improvement in VAS score was also significant $(\mathrm{p}<.001)$.

The response of burning sensation on the ingestion of spicy food was assessed by VAS scale and there was a subjective relief soon after the first visit. A study in patients suffering from chemotherapy induced mucositis showed that burning started after the termination of sesame oil application and was healed by restarting the oil application. Inflammation in oral mucosa caused by up regulation of genes regulating synthesis of proinflammatory cytokines due to activation of NF-kB is a critical event in message generation and signaling and amplification phase [16]. It was reported that sesamin treatment inhibited the activation of NF-kB induced bacterial chemotactic peptide. It was evaluated that inflammatory change was reduced by sesame oil application due to its anti-inflammatory effect.

No significant difference $(\mathrm{p}<.228)$ was seen in cheek flexibility. There was a significant difference seen between the pre and post values of the gingival index score. A significant reduction in colony count of $S$. mutans in plaque sample and decrease in plaque, gingival index score after oil pulling procedure. The process of oil pulling leads to generation of antioxidants which damage the cell wall of the microorganisms thereby killing them [17-19].

\section{Conclusion}

Sesame oil pulling proved highly effective in the management of oral submucous fibrosis with no side effects as compared to other 
treatment modalities available. However, further trials with a larger sample size and longer follow-up are required to investigate not only the efficacy of sesame oil pulling but also if it can be complemented with other treatment modalities for improvement of this chronic disease.

\section{Acknowledgements}

We would like to thank V.V.V Idhayam for their support to conduct the study.

\section{Conflicts of Interest and Funding}

None to declare.

\section{Bibliography}

1. Sodhi S., et al. "Expression of tumor necrosis factor alpha and its correlation with severity of oral submucous fibrosis: a case- control study". Oral Surgery, Oral Medicine, Oral Pathology, and Oral Radiology 117 (2004): 704-708.

2. Awadullah M., et al. "Management update of potentially premalignant oral epithelial lesions". Oral Surgery, Oral Medicine, Oral Pathology, and Oral Radiology 125 (2018): 628-636.

3. Caniff JP., et al. "Oral submucous fibrosis. Its pathogenesis and management". British Dental Journal 160 (1986): 429-434.

4. Arakeri G and Brennan PA. "Oral submucous fibrosis: an overview of the aetiology, pathogenesis, classification, and principles of management". British Journal of Oral and Maxillofacial Surgery 51 (2013): 587-593.

5. Angadi PV and Rao S. Management of oral submucous fibrosis: an overview". Oral and Maxillofacial Surgery 14 (2010): 133-142.

6. Vasant VS., et al. "Management of oral sub-mucous fibrosis: A review”. Indian Journal of Dental Sciences 2 (2012): 107-114.

7. Rajendran R. "Shafer's Textbook of Oral pathology". $6^{\text {th }}$ edition (2009): 96-100.

8. Parolia A. “Oil hygiene”. British Dental Journal 207 (2014): 408.

9. Asokan S., et al. "Effect of oil pulling on Streptococcus mutans count in plaque and saliva using Dentocult SM strip mutans test: A randomized, controlled, triple-blind study". Journal of Indian Society of Pedodontics and Preventive Dentistry 26 (2008): 12-17.
10. Asokan S., et al. "Effect of oil pulling on plaque induced gingivitis: A randomized, controlled, triple blind study". Indian Journal of Dental Research 20 (2009): 47-45.

11. Namiki M. "The chemistry and physiological functions of sesame”. Food Review International 11 (1995): 281-329.

12. Reddy V., et al. "Oral Submucous Fibrosis: Correlation of Clinical Grading to various habit factors". Journal of International Society of Preventive and Community 2 (2011): 21-24.

13. Soben Peters. "Essentials of public health dentistry". $5^{\text {th }}$ edition.

14. Haider SM., et al. "Clinical and functional staging of OSMF". British Journal of Oral and Maxillofacial Surgery 38 (2000): 1215.

15. Piyush P., et al. "Comparison of therapeutic response of lycopene and curcumin in oral submucous fibrosis: A randomized controlled trial". Oral Diseases (2019).

16. Maher RL., et al. "Role of areca nut in the causation of oral submucous fibrosis: a case control study in Pakistan". Journal of Oral Pathology and Medicine 2 (1994): 65-69.

17. Okada SS and Nishio J. "Topical application of sesame oil for the prevention of chemotherapy induced oral mucositis: Pilot Study in seven hematopoetic cancer patients". International Journal of Nursing and Clinical Practices 2 (2009): 123.

18. Asokan S. "Oil Pulling therapy". Indian Journal of Dental Research 19 (2008): 169.

19. Daar AS., et al. "Grand challenges in chronic non-communicable diseases". Nature 450 (2007): 494-496.

\section{Assets from publication with us}

- Prompt Acknowledgement after receiving the article

- Thorough Double blinded peer review

- Rapid Publication

- Issue of Publication Certificate

- High visibility of your Published work

Website: www.actascientific.com/

Submit Article: www.actascientific.com/submission.php

Email us: editor@actascientific.com

Contact us: +919182824667 